\title{
OPTICAL ABSORPTION OF POLYMER FILMS DOPED WITH BEDT-TTF POLYIODIDES
}

\author{
H.W. Helberg, D. Staerk \\ Third Physical Institute, University of Göttingen, D-37073 Göttingen, Germany \\ J. ULAŃSKI \\ Polymer Institute, Technical University of Łódż, Żwirki 36, 90-924 Lódź, Poland \\ AND J.K. JESZKA \\ Center of Molecular and Macromolecular Studies \\ Sienkiewicza 112, 90-363 Łódź, Poland
}

\begin{abstract}
Conducting reticulate doped polymeric films containing BEDT-TTF iodide crystalline network were annealed in order to transform the crystallites into crystal phases with metallic conductivity. Measured optical absorption spectra show that annealing shifts the absorption band to higher frequencies and increases the transparency of the films. This behavior corresponds to the transformation of the $\alpha$-phase into the superconducting $\alpha_{\mathrm{t}}$-phase observed in (BEDT-TTF) ${ }_{2} \mathrm{I}_{3}$ single crystals.

PACS numbers: $78.40 . \mathrm{Ha}, 78.30 . \mathrm{Jw}, 74.70 . \mathrm{K}_{\mathbf{n}}$
\end{abstract}

\section{Introduction}

Conducting polymeric materials have been prepared by reticulate doping [1]. A small amount $(\approx 2 \mathrm{wt} . \%)$ of an organic conducting salt or complex forms a continuous network of crystallites in the polymer matrix during the casting process. In addition a special casting technique yields conducting polymers with high anisotropy of the conductivity $[2,3]$.

Recently conducting reticulate doped polymer films have been prepared containing a low amount of organic salt crystallites, which are transformed into superconducting phases by annealing [4]. The attempt is to make use of the well known conversions of $\alpha$-(BEDT-TTF $)_{2} \mathrm{I}_{3}$ crystals into the superconducting phase $\alpha_{\mathrm{t}}$-(BEDT-TTF $)_{2} \mathrm{I}_{3}[5,6]$ or the transformations of the various BEDT-TTF polyiodides into the $\alpha$ - or $\beta^{*}$-phase of (BEDT-TTF) ${ }_{2} \mathrm{I}_{3} 7$ 7]. Such superconducting polymer films are very interesting due to their potential applications. The present paper deals with optical absorption spectra in dependence on annealing temperature and annealing time. 


\section{Experimental}

During casting an amount of $2 \mathrm{wt} . \%$ of BEDT-TTF is molecularly dispersed in polycarbonate films (film thickness $20 \mu \mathrm{m}$ ) [4]. Then one surface of the film is exposed to solvent/iodine vapor. In the swollen film the BEDT-TTF molecules become movable. In a small layer below the film surface reaction between BEDT-TTF and iodine takes place forming a thin conducting layer (thickness $\approx 5 \mu \mathrm{m}$ ) containing tiny microcrystals of BEDT-TTF polyiodide salts [4].

Annealings at $100,110,120$, and $130^{\circ} \mathrm{C}$ with several annealing times are applied to these films in order to transform the BEDT-TTF polyiodide crystallites into other crystal phases with metallic conductivity or even superconductivity (e.g. $\alpha_{\mathrm{t}}$-phase, $\beta^{*}$-phase) $[4,7]$.

The absorption spectra of the unannealed and annealed films are measured in the VIS and NIR spectral range ( $400 \mathrm{~nm}$ to $1 \mu \mathrm{m}$ ) using a special microscope photometer. Also the crystalline network in the films is examined in a polarizing microscope. The samples are treated together with samples which are used for measurements of the microwave conductivity [8].

\section{Results and discussion}

For comparison Fig. 1 shows the absorption for unpolarized light of the $\alpha$-phase and $\alpha_{t}$-phase of (BEDT-TTF) $)_{2} \mathrm{I}_{3}$ in the same crystal [9]. The absorption band of the $\alpha$-phase at $2.2 \times 10^{4} \mathrm{~cm}^{-1}$ is shifted to higher wave numbers. Also the optical density is lowered by about $20 \%$. The main bands result from intramolecular excitations in approximately (BEDT-TTF) ${ }^{0}\left(2.06 \times 10^{4} \mathrm{~cm}^{-1}\right)$, (BEDT-TTF $)^{+}\left(1.69,2.05\right.$, and $\left.2.17 \times 10^{4} \mathrm{~cm}^{-1}\right)$ [9-11], and also from a transition in the $\mathrm{I}_{3}^{+}$anion $\left(2.0 \times 10^{4} \mathrm{~cm}^{-1}\right)$ [12]. The small bands at $1.15 \times 10^{4} \mathrm{~cm}^{-1}$ are due to intermolecular excitations $[9,10]$. They are not shifted, but enhanced, i.e. the dimensionality increases due to annealing. In polarized light these effects are much more pronounced. There the absorption with light polarization parallel to the stack direction [100] is dominated by a band at $1.9 \times 10^{4} \mathrm{~cm}^{-1}$ broad extended to higher wave numbers [9]. Obviously this band $\left(\mathrm{I}_{3}^{+}\right)$originates the shoulder of the $\alpha$-phase in Fig. 1 at $1.7 \times 10^{4} \mathrm{~cm}^{-1}$.

The results after annealing of the films are shown in Figs. 2 to 4 for three different annealing temperatures. Without annealing the main band corresponds to the band of the $\alpha$-phase in single crystals (Fig. 1). Probably the broadening is due to the microcrystallinity and also due to the fact that certainly the majority of the crystallite network consists of $\alpha$-phase crystals. But in addition there are polyiodides involved, which have modified conversion processes or even decompose [7].

The shift to higher wave numbers depends strongly on the annealing temperature. An annealing temperature of $100^{\circ} \mathrm{C}$ is too low for conversion (Fig. 2). No remarkable shift and only a small enhancement of the transparency are observed. On the other hand, the annealing temperature of $130^{\circ} \mathrm{C}$ is very high (Fig. 4). Only few seconds of annealing are needed to finish the conversion. The shift is like in the single crystal (Fig. 1). The progress of conversion is best observed at an annealing temperature of $120^{\circ} \mathrm{C}$ (Fig. 3). An analogous behavior is found for the microwave conductivity [8]. 


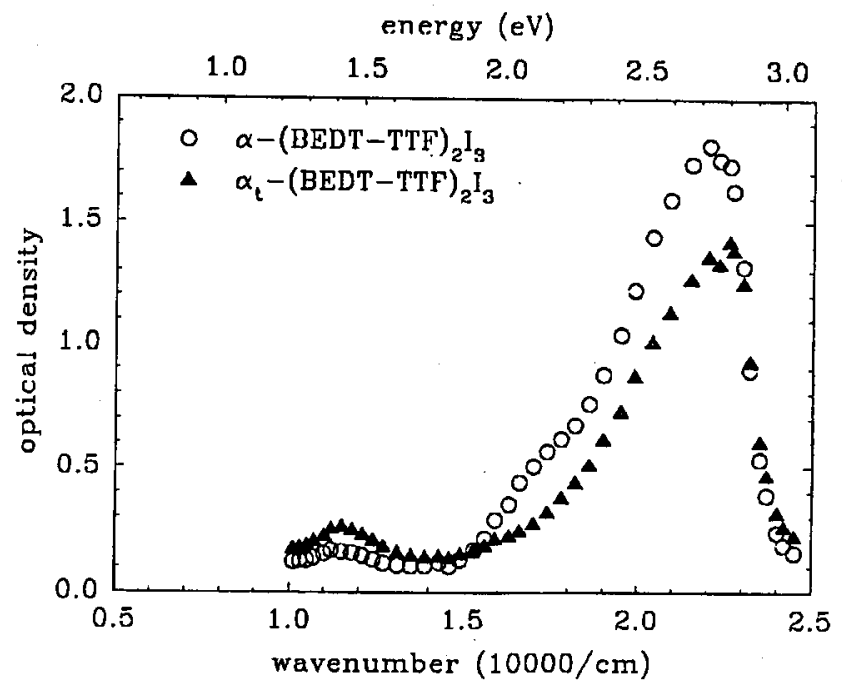

Fig. 1. Optical density versus wave number of the same $\alpha$-(BEDT-TTF $)_{2} \mathrm{I}_{3}$ crystal. One part of the crystal is transformed by annealing ( $\alpha_{\mathrm{t}}$-phase), the other part remained untransformed ( $\alpha$-phase) due to interruption of the transformation process [9]. Annealing temperature $78^{\circ} \mathrm{C}$. Annealing time 6.5 days. Unpolarized light beam, directed perpendicular to (001) of the $\alpha$-phase.

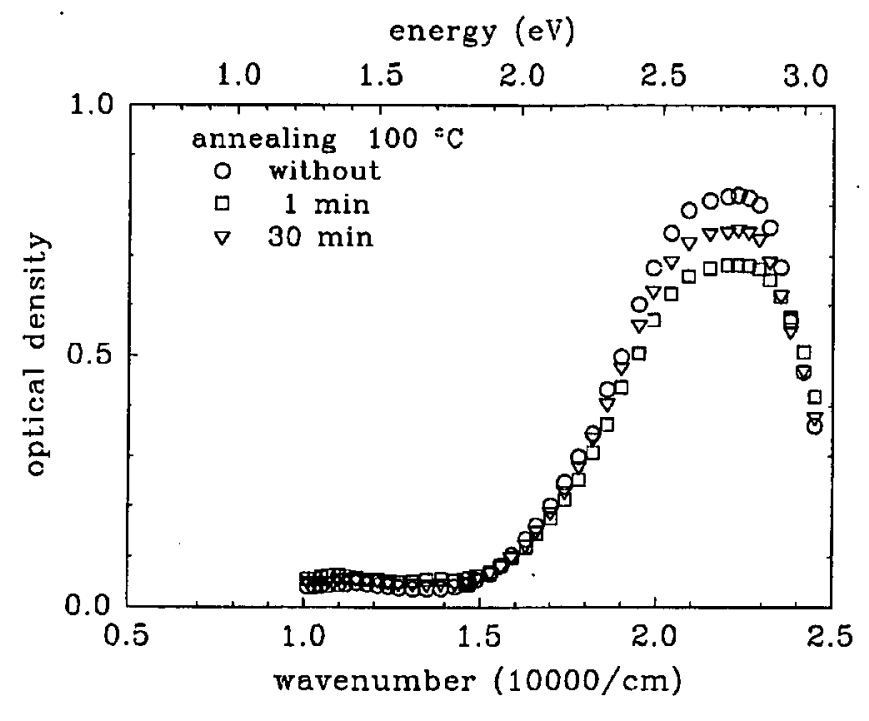

Fig. 2. Optical density versus wave number of a polycarbonate film, reticulate doped with BEDT-TTF polyiodides. Annealing temperature $100^{\circ} \mathrm{C}$. Varied annealing times.

The decrease in the optical density is more pronounced in the films and amounts between 15 and $45 \%$ for 100 and $130^{\circ} \mathrm{C}$, respectively. 


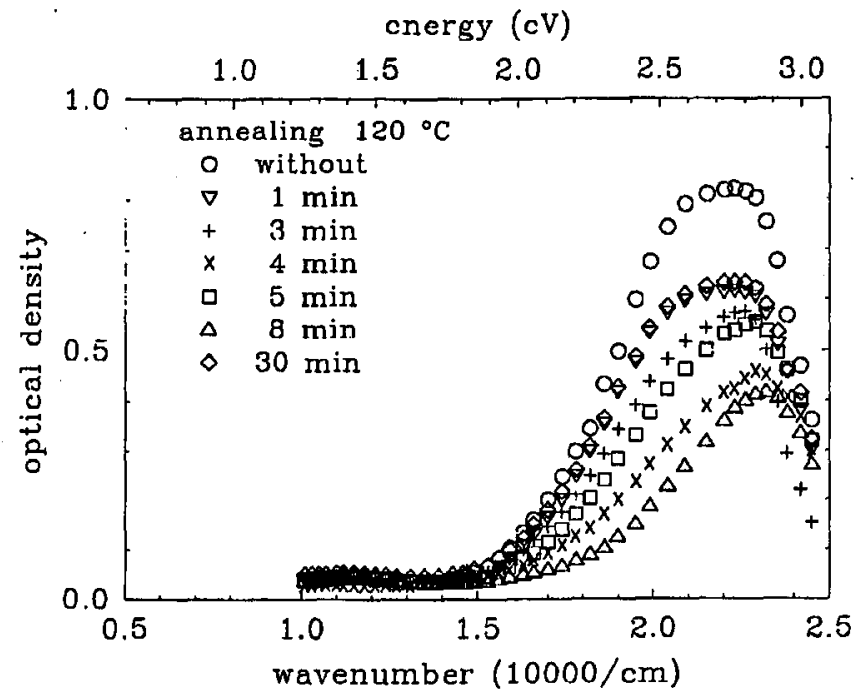

Fig. 3. Optical density versus wave number of a polycarbonate film, reticulate doped with BEDT-TTF polyiodides. Annealing temperature $120^{\circ} \mathrm{C}$. Varied annealing times.

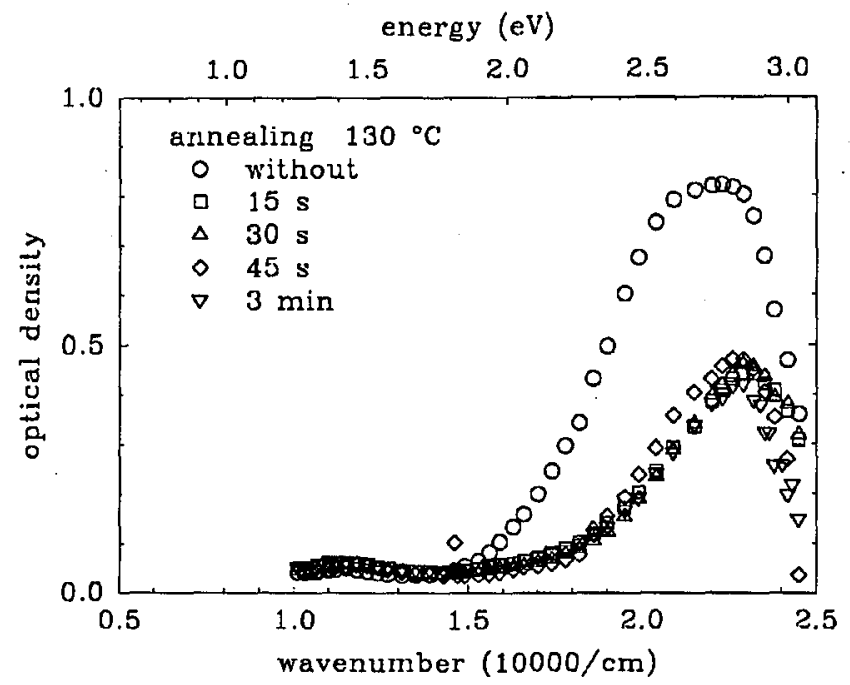

Fig. 4. Optical density versus wave number of a polycarbonate film, reticulate doped with BEDT-TTF polyiodides. Annealing temperature $130^{\circ} \mathrm{C}$. Varied annealing times.

Shift and decrease are not always in the right sequence related to the annealing temperature. Reasons may be nonuniform film preparation, decomposition of crystallite components, different conversion processes for the different components, and changes in the arrangement (interaction) of the microcrystals (diameter about 1 to $2 \mu \mathrm{m}$ ). A similar behavior is observed when starting the annealing of pressed $\alpha$-(BEDT-TTF $)_{2} \mathrm{I}_{3}$ microcrystals [13]. 


\section{Acknowledgment}

J.U. and J.K.J. of us acknowledge the support from Project 300909101 of the State Committee for Scientific Research (Republic of Poland).

\section{References}

[1] J.K. Jeszka, J. Ulański, M. Kryszewski, Nature 289, 390 (1981).

[2] L. Burda, A. Tracz, T. Pakula, J. Ulański, M. Kryszewski, J. Phys. D, Appl. Phys. 16, 1737 (1983).

[3] M. Kryszewski, J.K. Jeszka, J. Ulański, A. Tracz, Pure Appl. Chem. 56, 355 (1984).

[4] J. Ulański, J.K. Jeszka, A. Tracz, I. Głowacki, M. Kryszewski, E. Laukhina, Synth. Met. 56, 2001 (1993).

[5] G.O. Baram, L.I. Buravov, L.S. Degtyarev, M.E. Kozlov, V.N. Laukhin, E.E. Laukhina, V.G. Onishchenko, K.I. Pokhodnya, M.K. Sheinkman, R.P. Shibaeva, E.B. Yagubskii, Pis'ma Zh. Eksp. Teor. Fiz. 44, 293 (1986).

[6] D. Schweitzer, P. Bele, H. Brunner, E. Gogu, U. Haeberlen, I. Hennig, I. Klutz, R. Swietlik, H.J. Keller, Z. Phys. B, Condens. Matter 67, 489 (1987).

[7] L.I. Buravov, A.V. Zvarykina, E.E. Laukhina, V.N. Laukhin, R.M. Lobkovskava, V.A. Merzhanov, N.N. Alejnikov, R.P. Shibaeva, I.F. Shchegolev, E.B. Yagubskii, Mater. Sci. 14, 17 (1988).

[8] D. Staerk, H.W. Helberg, J. Ulański, J.K. Jeszka, Acta Phys. Pol. A 87, (1995).

[9] H.W. Helberg, D. Schweitzer, H.J. Keller, Synth. Met. 27, A347 (1988).

[10] H.W. Helberg, Ber. Bunsenges. Phys. Chem. 91, 899 (1987).

[11] K.I. Pokhodnya, Thesis, Institute of Semiconductors, Academy of Sciences of the Ukraine, Kiev 1993.

[12] W. Gabes, D.J. Stukkens, Spectrochim. Acta A 30, 1835 (1974).

[13] G. Müller, H.W. Helberg, D. Schweitzer, H.J. Keller, Synth. Met. 42, 1999 (1991). 